\title{
Statistical validation of physiological indicators for non- invasive and hybrid driver drowsiness detection system
}

\author{
Eugene Zilberg ${ }^{1}$, Zheng Ming Xu ${ }^{1}$, David Burton ${ }^{1}$, Murad Karrar ${ }^{1,2}$, and Saroj Lal ${ }^{2}$ \\ ${ }^{1}$ Compumedics Medical Innovation Pty Ltd \\ 30-40 Flockhart St Abbotsford 3067 Australia \\ Email: ezilberg@,compumedics.com.au,MingXu@,compumedics.com.au, \\ dburton@compumedics.com.au,.muradkarrar@compumedics.com.au. \\ ${ }^{2}$ University of Technology Sydney (UTS) \\ Broadway NSW 2007 Australia \\ Email: Sara.Lal@uts.edu.au.
}

\begin{abstract}
A hybrid system for detecting driver drowsiness was examined by using piezofilm movement sensors integrated into the car seat, seat belt and steering wheel. Statistical associations between increase in the driver drowsiness and the non-invasive and conventional physiological indicators were investigated. Statistically significant associations were established for the analysed physiological indicators - car seat movement magnitude and (electroencephalogram) EEG alpha band power percentage. All of the associastions were physiologically plausible with increase in probability of drowsiness associated with increases in the EEG alpha band power percentage and reduction in the seat movement magnitude. Adding a non-invasive measure such as seat movement magnitude to any combination of the EEG derived physiological predictors always resulted in improvement of associations. These findings can serve as a foundation for designing the vehicle-based fatigue countermeasure device as well as highlight potential difficulties and limitations of detection algorithm for such devices.
\end{abstract}

Index Terms-driver fatigue, drowsiness, detection algorithm, seat movements, EEG, alpha activity.

\section{INTRODUCTION}

Driver drowsiness is recognised as an important factor in the motor vehicle accidents $[4,10,15]$. It has been shown that a number of physiological indicators such as the spectral content of electroencephalogram (EEG) $[9,11,12,17]$, blink rate [20], individual blink parameters [2] and degree of eye closure (PERCLOS) [5] are associated with the increase in drowsiness [10] and can respectively be used for detecting driver drowsiness.

Compumedics Medical Innovation Pty Ltd, Australia proposed application of non-invasive piezofilm movement sensors that can be incorporated into car seat, seat belt and steering wheel [1]. These sensors are potentially capable of recording patterns of driver's movements, breathing and even heart rate that could be used for identifying the level of drowsiness. Another aspect of Compumedics patented technology includes integration of different kinds of signal analysis including morphological processing of EEG and eye movement patterns that was successfully used for automatic analysis of sleep recordings [16].

The objective of this article is to establish statistical associations between increase in the driver drowsiness and the non-invasive physiological indicators proposed by Compumedics as well as to demonstrate increase in the strength of these associations in the hybrid system when a "gold standard" indicator (EEG spectral content) is combined with the non-invasive piezofilm movement sensors embedded in the car seat. The identified statistical associations can serve as a foundation for designing the vehicle-based fatigue countermeasure device as well as highlight potential difficulties and limitations of detection algorithm for such devices.

This article follows the earlier investigations [24, 25 ] that described the driver simulator study conducted as a part of the ARC Linkage grant with University of Technology Sydney, Australia, to explore possibilities offered by the Compumedics non-invasive and hybrid 
technologies, introduced the observer driver drowsiness scale, explained the data analysis methodology and presented results of statistical analysis focusing on investigation of associations between transition to a state of drowsiness and patterns of selected physiological indicators including the surface movements of the seat and steering wheel, EEG and durations of eye movements.

\section{METHODS}

\section{A. Car simulator study and data selection}

A car simulator study comprising 60 nonprofessional fully licensed drivers was conducted at the Monash University Accident Research Centre (MUARC) in 2005-2006 [24, 25]. The objective of this study was to record multitude of physiological signals that could be potentially used as components in the driver drowsiness detection algorithm as well as a number of measures that could be employed as independent indicators of the drowsiness level. The recorded physiological signals included 10 EEG channels, chin EMG (electromyogram), ECG (electrocardiogram), left and right EOG (electrooculogram), eyelid movement sensor, thoracic respiratory band, 8 steering wheel pressure gauge signals and multiple signals from the piezofilm sensors located on the car seat and steering wheel. The movement sensors included 7 sensors on the steering wheel, 5 on the back of the seat and 5 on the bottom section of the seat. Siesta portable sleep diagnostic recording system (Compumedics Pty Ltd, Australia) was used for physiological data recording. The information for the independent assessment of the drowsiness level included 4 video signals, estimate of PERCLOS [5] from the FaceLAB system [7] as well as a list of driving performance parameters. The participants also filled a number of pre- and post-study questionnaires such as Lifestyle Questionnaire [4], profile of mood states [14], and anxiety state-trait [19].

The developed observer drowsiness rating scale [24] included 5 levels similar to those described in [22] - from alert to extremely drowsy and was based on observing a number of indicators including duration and rate of eye blinks and other eye lid movements, degree and duration of eye closures, direction and focus of eye gaze, patterns of facial, hand and other body movements, yawning etc. The appropriate dangerous level of drowsiness was selected as "significantly drowsy" (level 3) based on appearance of eye closure episodes.

\section{B. Statistical associations in question}

In $[24,25]$ we conducted statistical analyses of the time courses of different physiological indicators during episodes of transitions to the state of significant drowsiness. The main findings of these analyses were

- There was a pattern of reduction in the magnitude of seat movements associated with transition to the state of significant drowsiness with the sensors on the back of the seat demonstrating more significant association than those on the bottom of the seat;

- There was a pattern of increase in the percentage of EEG alpha activity associated with transition to the state of significant drowsiness for the central and occipital EEG derivations with the former derivation demonstrating more significant association when correlation is taken into account;

- There was a pattern of increase in the duration of eye movements associated with transition to the state of significant drowsiness with eye movements scored from the frontal EEG. The eye movement duration calculated from the eyelid movement sensor signal demonstrating more significant association than that scored from EEG (although this finding is based on a very small subset of participants);

- There was a pattern of reduction in the magnitude of steering wheel surface movement and pressure associated with transition to the state of significant drowsiness with the movement sensors demonstrating significant association in contrast to the pressure and both measures having substantially less significant associations than the seat movement.

Although the method of analysis of the time course of physiological indicators during transition to drowsiness state by means of fitting linear regression models with the correlated observations [3,18,21] enabled to establish the described associations there were still a number of important questions that it could not help to answer

- What is the association between physiological indicators and probability of a predetermined state of drowsiness?

- How can different physiological indicators be compared in relation to their association with the probability of drowsiness?

- How can different physiological indicators be combined to increase the strength of association with the probability of drowsiness 
and what is the contribution of individual measures into the increased association?

Fitting the binary (and potentially nominal/ordinal logistic regression models [6]) can potentially address these issues.

\section{Statistical models}

The most general approach to define the outcome variable would be to use the same set of categories as in the visual scale of drowsiness described in [24,25]. However as a starting point for analysis covered in this article we employed a binary model with the state of drowsiness being defined as the drowsiness level of 3 (significant drowsiness) or higher while the state of alertness being defined as any drowsiness level below 3 .

Only the observations recorded during the episodes of transition to drowsiness were used in this analysis. The rationale for this is that initially we had to establish associations that are specific for those most important episodes unaffected by other factors that could be present during states of prolonged alertness or deeper drowsiness. If no statistically significant associations are found for the episodes of transition to drowsiness the expansion of this method to longer time intervals would be pointless.

The observation values for covariates for this analysis are formed in the following way. All episodes of transition to significant drowsiness are divided into non-overlapping 20 second segments. The selection of $20 \mathrm{~s}$ interval was a trade-off between $30 \mathrm{~s}$ intervals employed in [24] to analyse the seat movement and eye movement duration and $10 \mathrm{~s}$ intervals used for he EEG analysis. For every segment the following values are calculated

- The maximum drowsiness rating out of the two 10 second intervals that comprise the 20 second segement;

- Seat piezofilm movement sensor data for all 10 seat sensors calculated as explained in the section on the time course analysis but averaged over 20 s segments;

- $\mathrm{C} 4$ and O2 EEG derivation data with the maximum $2 \mathrm{~s}$ alpha band percentage calculated over 20 s segments;

- $\quad$ Eye movement duration data derived from the frontal EEG and averaged over $20 \mathrm{~s}$ segments.
The total number of observations with valid nonzero values of all covariates for 115 episodes of transition to drowsiness was 1029 .

If correlation between observations is ignored the binary logistic model for the log odds of drowsiness and a combination of $N$ covariates can be formulated in a general form [20] as

$$
\log \left[\frac{\operatorname{Pr}\left\{Y_{i}\right\}}{1-\operatorname{Pr}\left\{\mathrm{Y}_{\mathrm{i}}\right\}}\right]=\beta_{0}+\sum_{k=1}^{N} \beta_{k} \text { COVAR }_{k i}
$$

where

- $\quad Y_{i}$ - binary state of drowsiness for the $i^{\text {th }}$ observation;

- $C O V A R_{k i}$ - value of the $k^{\text {th }}$ covariate for the $i^{\text {th }}$ observation;

- $\beta_{0}, \beta_{k}$ - regression coefficients to be estimated with the coefficient $\beta_{k}$ representing the effect of the $k^{\text {th }}$ covariate.

The graphical example of fitting the model (1) for the case of central EEG derivation $\mathrm{C} 4$ as a single covariate is presented in Figure 1. To generate this graph all 1029 observations were put into one of 100 bins based on the respective nearest integer to the value of the $\mathrm{C} 4$ alpha percentage. For every bin the observed proportion of observations with significant drowsiness was calculated. Then the univariate binary logistic regression model was fitted and the predicted proportions of drowsiness were generated for every bin. It is evident that binary logistic model is an adequate method for description of association between increase of the alpha percentage and odds of drowsiness.

The set of covariates in (1) was expanded to include the observations of respective physiological parameters at the preceding $20 \mathrm{~s}$ segments (denoted with index previous) as well observations referenced to the value in the start of a respective transition episode (trajectory) segments (denoted with the additional index ref). The observations of covariates at the given $20 \mathrm{~s}$ segment was denoted by the index recent. Finally the observations for the preceding $20 \mathrm{~s}$ second segment referenced to the start of the trajectory will be denoted with the index previous_ref. The preceding segments were included in the regression model to investigate the predictive capabilities of different physiological indicators while referencing to the start of a trajectory is important for the covariates that have no 
physiological interpretation for their absolute values (like seat movement magnitude).

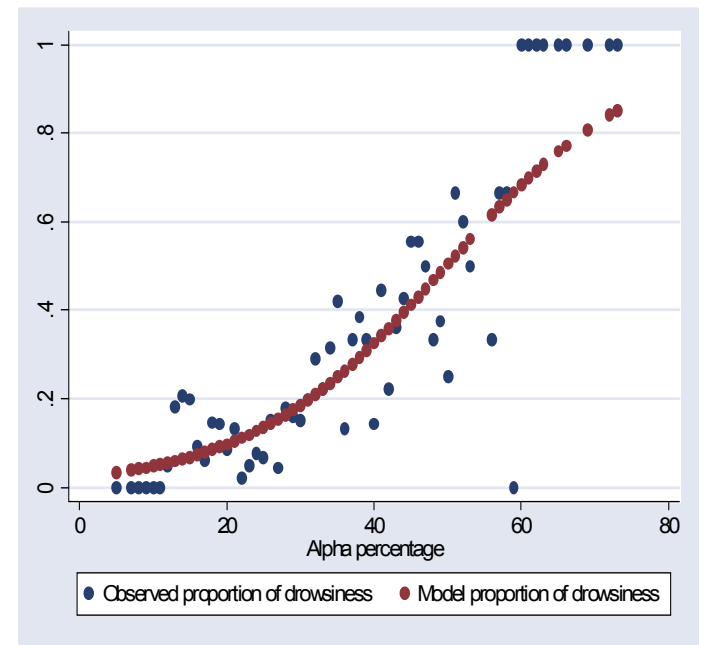

Figure 1. Fitting binary logistic regression model for association between alpha band percentage for the central EEG derivation and odds of drowsiness

Correlation between observations can be taken into account by means of fitting the random-effects non-linear mixed model $[8,23]$

$$
\log \left[\frac{\operatorname{Pr}\left\{Y_{i j}\right\}}{1-\operatorname{Pr}\left\{\mathrm{Y}_{\mathrm{ij}}\right\}}\right]=\beta_{0}+b_{i}+\sum_{k=1}^{N} \beta_{k} \text { COVAR }_{k i j}
$$

where

- $\quad Y_{i j}$ - binary state of drowsiness for the $j^{\text {th }}$ observation of the $i^{\text {th }}$ cluster (eg. trajectory);

- $C O V A R_{k i j}$ - value of the $k^{\text {th }}$ covariate for the $j^{\text {th }}$ observation of the $i^{\text {th }}$ cluster;

- $b_{i}$ - zero-mean normal error component for the $i^{\text {th }}$ cluster.

The models were ranked by means of comparing their log-likelihood statistics and deviances and the objective was to obtain the parsimonious (simplest statistically significant) models for the given combinations of physiological indicators. The diagnostic capabilities of the fitted combinations of covariates were indicatively compared by means of estimating the areas under the respective Relative Operating Characteristic (ROC) curves.

The analysis started with the EEG alpha percentage that is known to be an important contributor into EEG based drowsiness rating $[9,11,12,17]$. Then diagnostic capabilities of other variables and combinations of variables were investigated with performance of the EEG based measure used as a benchmark.

\section{RESUltS}

\section{A. $E E G$}

The parsimonious models with multiple EEG parameters are presented in Table 1. For different correlation assumption different combination of four EEG parameters were found to maximize the loglikelihood. In all cases the estimated values of all regression coefficients were positive as expected. It appears that combination of central and occipital EEG derivations as well as adding the observation for preceding time interval improved fit of the respective regression models. The final log-likelihood of -399.42 , -382.74 and -370.74 will be used as respective benchmark values in the course of the further analyses involving other physiological variables. Finally the typical ROC for the combination of EEG covariates estimated for the random-effects model (2) and withintransition correlation is displayed in Figure 2.

\section{B. Piezofilm seat movement sensors}

The results of fitting models $(2,3)$ for combinations of all seat sensor observations and the parsimonious combination of these sensors are presented in the Tables 2 and 3 respectively. Even when all seat movement sensor signals are combined the log-likelihood is considerably lower than for EEG. The high level of correlation and subsequent redundancy between the seat movement sensors is highlighted by the fact that the parsimonious models only require 3 or even 2 (when correlation between observation is taken into account) parameters. The negative signs of all regression coefficients in the parsimonious models confirm the fundamental assumption that reduction in the seat movement magnitude is associated with transition to drowsiness.

For the parsimonious models there is a massive difference of 76.76 in the values of log-likelihood between the seat movement and EEG models (for the case within-transition episode correlation). Finally the ROC curve for one of the parsimonious models for seat movements is presented in Figure 3.

\section{Combination of EEG and seat movement magnitude}

The parsimonious models for the combination of EEG and seat movement magnitude are presented in Table 4. It is evident that replacing one of the EEG covariates with a seat movement signal significantly 
increases the log-likelihood. The ROC curve for one of the parsimonious models for a combination of EEG and seat movements' magnitude is presented in Figure 4.

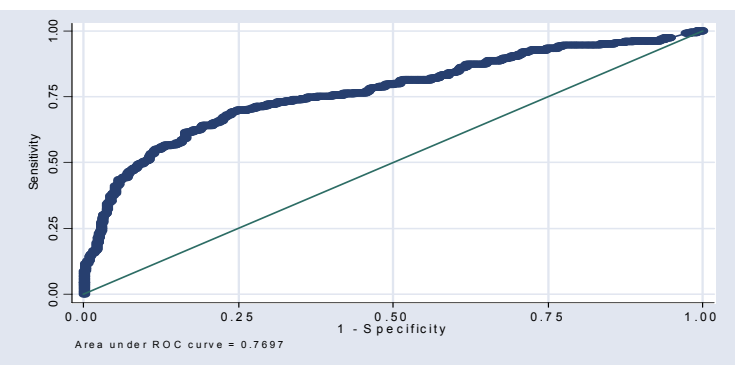

Figure 2. ROC curve for the parsimonious model with the central and occipital EEG sensor signals as parameters

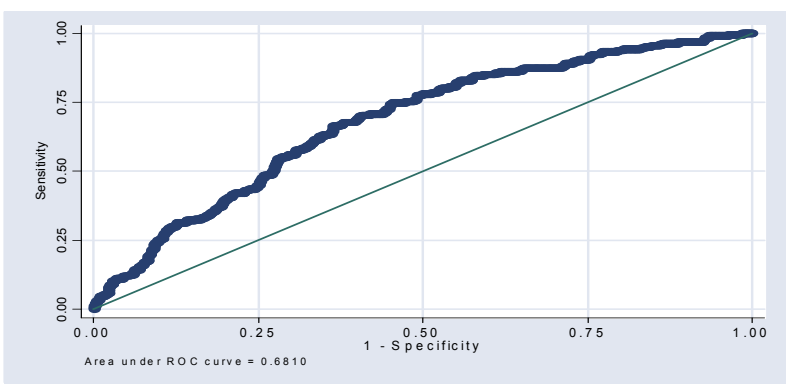

Figure 3. ROC curve for the parsimonious model with the seat movement sensor signals as parameters

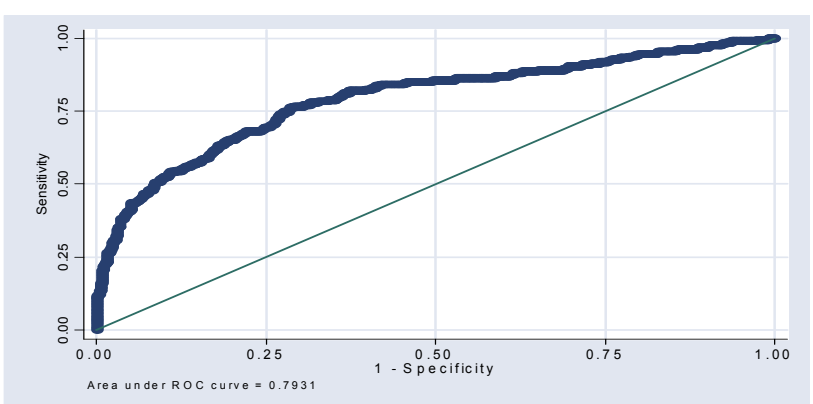

Figure 4. ROC curve for the parsimonious model with EEG alpha percentage and seat movement data as parameters

\section{DISCUSSION}

The most important findings of the conducted analysis of associations between probability of drowsiness and selected physiological indicators of drowsiness over the course of episodes of transition to drowsiness are:

- Statistically significant associations were established for the analysed physiological indicators - EEG alpha band power percentage and seat movement magnitude. Directions of all associations were physiologically plausible with increase in probability of drowsiness associated with increases in the EEG alpha band power percentage and reduction in the seat movement magnitude;

- The "gold standard" EEG alpha percentage demonstrated the most significant association with the probability of drowsiness and model with the seat movement magnitude has the poorest fit.

- Adding a non-invasive measure that is seat movement magnitude to any parsimonious combination of the EEG derived physiological predictors always resulted in statistically significant improvement of associations;

- The diagnostic accuracy as measured by the area under ROC curve was relatively poor (for an effective practical use of the fitted models) for all combinations of analysed parameters implying the need for more sophisticated derivations of the measured signals. This observation was not unexpected as the signal processing methods used in the analysis were relatively simplistic. The combinations of EEG alpha percentage and seat movement magnitude were found to have largest values of the area under the ROC curve.

This article presented the statistical methodology for analysis of associations between the driver drowsiness and accompanying physiological indicators. The main conclusions are that the noninvasive measures of body movement recorded with piezofilm sensors located inside the car seat demonstrated statistically significant association with the state significant drowsiness and also improved associations with drowsiness when used in combination with other physiological measures namely EEG alpha percentage. 
Table 1. Parsimonious binary logistic regression models for central and occipital EEG derivations as covariates and log odds of drowsiness outcome with different correlation assumptions

\begin{tabular}{|c|c|c|c|c|c|}
\hline \multicolumn{2}{|c|}{ Correlation model } & Covariate 1 & Covariate 2 & Covariate 3 & Covariate 4 \\
\hline \multirow{6}{*}{$\begin{array}{l}\text { Independent } \\
\text { observations }\end{array}$} & Covariate & C4_recent & C4_previous_ref & O2_recent_ref & $\mathrm{O} 2$ previous \\
\hline & $\begin{array}{l}\text { Regression } \\
\text { coeff. }\end{array}$ & $\begin{array}{c}3.67 \\
{[1.87 ; 5.47]}\end{array}$ & $\begin{array}{c}1.84 \\
{[0.27 ; 3.38]}\end{array}$ & $\begin{array}{c}3.77 \\
{[2.09 ; 5.45]}\end{array}$ & $\begin{array}{c}3.57 \\
{[2.07 ; 5.07]} \\
\end{array}$ \\
\hline & $\mathrm{z}$ & 4.00 & 2.34 & 4.40 & 4.67 \\
\hline & p-value & $<0.001$ & 0.019 & $<0.001$ & $<0.001$ \\
\hline & Log-likelihood & \multicolumn{4}{|c|}{-399.72} \\
\hline & A-ROC & \multicolumn{4}{|c|}{$0.765[0.726 ; 0.804]$} \\
\hline \multirow{6}{*}{$\begin{array}{c}\text { Within same } \\
\text { transition } \\
\text { episode } \\
\text { (random effects) }\end{array}$} & Covariate & C4_recent_ref & C4_previous & O2_recent_ref & O2_previous \\
\hline & $\begin{array}{l}\text { Regression } \\
\text { coeff. }\end{array}$ & $\begin{array}{c}5.26 \\
{[2.72 ; 7.79]} \\
\end{array}$ & $\begin{array}{c}3.96 \\
{[1.39 ; 6.53]} \\
\end{array}$ & $\begin{array}{c}5.12 \\
{[2.69 ; 7.55]}\end{array}$ & $\begin{array}{c}5.14 \\
{[2.68 ; 7.60]} \\
\end{array}$ \\
\hline & $\mathrm{Z}$ & 4.06 & 3.01 & 4.13 & 4.09 \\
\hline & p-value & $<0.001$ & 0.003 & $<0.001$ & $<0.001$ \\
\hline & Log-likelihood & \multicolumn{4}{|c|}{-382.74} \\
\hline & A-ROC & \multicolumn{4}{|c|}{$0.770[0.0 .731 ; 0.808]$} \\
\hline \multirow{6}{*}{$\begin{array}{c}\text { Between all } \\
\text { observations for } \\
\text { subject } \\
\text { (random effects) }\end{array}$} & Covariate & C4_recent & C4_previous & O2_recent_ref & $\mathrm{O} 2$ previous \\
\hline & $\begin{array}{c}\text { Regression } \\
\text { coeff. }\end{array}$ & $\begin{array}{c}7.14 \\
{[4.67 ; 9.61]}\end{array}$ & $\begin{array}{c}4.29 \\
{[1.72 ; 6.86]} \\
\end{array}$ & $\begin{array}{c}4.64 \\
{[2.71 ; 6.56]} \\
\end{array}$ & $\begin{array}{c}4.98 \\
{[2.88 ; 7.08]} \\
\end{array}$ \\
\hline & $\mathrm{Z}$ & 5.67 & 3.27 & 4.71 & 4.64 \\
\hline & $\mathrm{p}$-value & $<0.001$ & 0.001 & $<0.001$ & $<0.001$ \\
\hline & Log-likelihood & \multicolumn{4}{|c|}{-370.34} \\
\hline & A-ROC & \multicolumn{4}{|c|}{$0.756[0.715 ; 0.796]$} \\
\hline
\end{tabular}

Key: C4- central site, O2- occipital site, A-ROC is the area under Relative Operating Characteristic (ROC) curve, $p$ value $=$ significance level, $\mathrm{Z}$ is the ratio of estimate to its standard deviation.

Table 2. Multivariate binary logistic regression for different combinations of seat movement sensor as covariates and log odds of drowsiness outcome with different correlation assumptions

\begin{tabular}{|c|c|c|c|}
\hline \multicolumn{2}{|c|}{ Correlation model } & \multirow{2}{*}{$\begin{array}{l}\text { preceding values for all sensors } \\
\text { (10 parameters) } \\
-461.129\end{array}$} & \multirow{2}{*}{$\begin{array}{l}\text { Latest and preceding values } \\
\text { for all sensors } \\
(20 \text { parameters }) \\
-452.026\end{array}$} \\
\hline Independent & Log-likelihood & & \\
\hline Observations & A-ROC & $0.673[0.632 ; 0.713]$ & $0.682[0.642 ; 0.721]$ \\
\hline \multirow{2}{*}{$\begin{array}{l}\text { Within same } \\
\text { transition episode } \\
\text { (random effects } \\
\end{array}$} & Log-likelihood & -454.907 & -443.599 \\
\hline & A-ROC & $-0.668[0.627 ; 0.708]$ & $0.677[0.639 ; 0.716]$ \\
\hline \multirow{2}{*}{$\begin{array}{c}\text { Between all } \\
\text { observations for } \\
\text { subject } \\
\text { (random effects }\end{array}$} & Log-likelihood & -454.877 & -445.583 \\
\hline & A-ROC & $0.671[0.630 ; 0.712]$ & $0.682[0.643 ; 0.721]$ \\
\hline
\end{tabular}

Key: A-ROC is the area under Relative Operating Characteristic (ROC) curve 
Table 3. Parsimonious binary logistic regression models for movement sensor as covariates and log odds of drowsiness outcome with different correlation assumptions

\begin{tabular}{|c|c|c|c|c|}
\hline \multicolumn{2}{|c|}{ Correlation model } & Covariate 1 & Covariate 2 & Covariate 3 \\
\hline \multirow{6}{*}{$\begin{array}{l}\text { Independent } \\
\text { observations }\end{array}$} & Covariate & Seat1_previous_ref & Seat1_recent_ref & Seat5_recent_ref \\
\hline & $\begin{array}{l}\text { Regression } \\
\text { coeff. }\end{array}$ & $\begin{array}{c}-46.36[-73.36 ;- \\
19.37] \\
\end{array}$ & $-27.55[-52.66 ;-2.45]$ & $-70.46[-120.26 ;-20.65]$ \\
\hline & $\mathrm{z}$ & -3.37 & -2.15 & -2.77 \\
\hline & $p$-value & 0.001 & 0.031 & 0.006 \\
\hline & Log-likelihood & \multicolumn{3}{|c|}{-466.22} \\
\hline & A-ROC & \multicolumn{3}{|c|}{$0.682[0.644 ; 0.720]$} \\
\hline \multirow{6}{*}{$\begin{array}{c}\text { Within same } \\
\text { transition episode } \\
\text { (random effects) }\end{array}$} & Covariate & Seat1_recent_ref & Seat4_previous_ref & \\
\hline & $\begin{array}{l}\text { Regression } \\
\text { coeff. }\end{array}$ & $\begin{array}{c}-57.12[-83.55 ;- \\
30.70] \\
\end{array}$ & $-46.24[-66.61 ;-25.87]$ & - \\
\hline & $\mathrm{z}$ & -4.24 & -4.45 & - \\
\hline & $p$-value & $<0.001$ & $<0.001$ & - \\
\hline & Log-likelihood & \multicolumn{3}{|c|}{-459.02} \\
\hline & A-ROC & \multicolumn{3}{|c|}{$0.681[0.643 ; 0.719]$} \\
\hline \multirow{6}{*}{$\begin{array}{c}\text { Between all } \\
\text { observations for } \\
\text { subject } \\
\text { (random effects) }\end{array}$} & Covariate & Seat1_recent_ref & Seat4_previous_ref & \\
\hline & $\begin{array}{l}\text { Regression } \\
\text { coeff. }\end{array}$ & $\begin{array}{c}-48.30[-69.80 ;- \\
26.80] \\
\end{array}$ & $-40.51[-58.58 ;-22.44]$ & - \\
\hline & $\mathrm{z}$ & -4.40 & -4.39 & - \\
\hline & $p$-value & $<0.001$ & $<0.001$ & - \\
\hline & Log-likelihood & \multicolumn{3}{|c|}{-460.48} \\
\hline & A-ROC & \multicolumn{3}{|c|}{$0.681[0.644 ; 0.719]$} \\
\hline
\end{tabular}

Key: A-ROC is the area under Relative Operating Characteristic (ROC) curve, $p$-value $=$ significance level, $\mathrm{z}$ is the ratio of estimate to its standard deviation.

Table 4. Parsimonious binary logistic regression models for combination EEG alpha band percentages and movement sensor signals as covariates and log odds of drowsiness outcome

\begin{tabular}{|c|c|c|c|c|c|}
\hline \multicolumn{2}{|c|}{ Correlation model } & Covariate 1 & Covariate 2 & Covariate 3 & Covariate 4 \\
\hline \multirow{6}{*}{$\begin{array}{l}\text { Independent } \\
\text { observations }\end{array}$} & Covariate & C4_recent & O2_recent_ref & O2_previous & Seat1_previous_ref \\
\hline & $\begin{array}{l}\text { Regression } \\
\text { coeff. }\end{array}$ & $\begin{array}{c}3.96 \\
{[2.12 ; 5.79]}\end{array}$ & $\begin{array}{c}4.54 \\
{[2.92 ; 6.16]}\end{array}$ & $\begin{array}{c}3.71 \\
{[2.25 ; 5.18]}\end{array}$ & $\begin{array}{c}-71.23 \\
{[-96.45-46.00]}\end{array}$ \\
\hline & $\mathrm{Z}$ & 4.23 & 5.50 & -3.44 & -4.40 \\
\hline & p-value & $<0.001$ & $<0.001$ & 0.001 & $<0.001$ \\
\hline & Log-likelihood & \multicolumn{4}{|c|}{-385.69} \\
\hline & A-ROC & \multicolumn{4}{|c|}{$0.793[0.757 ; 0.829]$} \\
\hline \multirow{6}{*}{$\begin{array}{l}\text { Within same } \\
\text { trans. episode } \\
\text { (random effects) }\end{array}$} & Covariate & C4_recent & O2_recent_ref & $\mathrm{O} 2$ previous & Seat1_previous_ref \\
\hline & $\begin{array}{l}\text { Regression } \\
\text { coeff. }\end{array}$ & $\begin{array}{c}6.03 \\
{[3.54 ; 8.52]} \\
\end{array}$ & $\begin{array}{c}5.50 \\
{[3.27 ; 7.73]} \\
\end{array}$ & $\begin{array}{c}5.46 \\
{[3.31 ; 7.62]} \\
\end{array}$ & $\begin{array}{c}-77.96 \\
{[-110.91 ;-45.02]}\end{array}$ \\
\hline & $\mathrm{z}$ & 4.75 & 4.83 & 4.97 & -4.64 \\
\hline & $\mathrm{p}$-value & $<0.001$ & $<0.001$ & $<0.001$ & $<0.001$ \\
\hline & Log-likelihood & \multicolumn{4}{|c|}{-374.42} \\
\hline & A-ROC & \multicolumn{4}{|c|}{$0.790[0.753 ; 0.827]$} \\
\hline \multirow{6}{*}{$\begin{array}{c}\text { Between all } \\
\text { observations for } \\
\text { subject } \\
\text { (random effects) }\end{array}$} & Covariate & C4_recent & O2_recent_ref & $\mathrm{O} 2$ previous & Seat1_previous_ref \\
\hline & $\begin{array}{l}\text { Regression } \\
\text { coeff. }\end{array}$ & $\begin{array}{c}6.37 \\
{[5.80 ; 10.97]} \\
\end{array}$ & $\begin{array}{c}4.44 \\
{[2.48 ; 6.39]}\end{array}$ & $\begin{array}{c}6.23 \\
{[4.38 ; 8.08]} \\
\end{array}$ & $\begin{array}{c}-71.20 \\
{[-99.00 ;-43.41]}\end{array}$ \\
\hline & $\mathrm{Z}$ & 6.37 & 4.45 & 6.60 & -5.02 \\
\hline & $\mathrm{p}$-value & $<0.001$ & $<0.001$ & $<0.001$ & $<0.001$ \\
\hline & Log-likelihood & \multicolumn{4}{|c|}{-361.59} \\
\hline & A-ROC & \multicolumn{4}{|c|}{$0.784[0.746 ; 0.821]$} \\
\hline
\end{tabular}

Key: C4- central site, O2- occipital site, A-ROC is the area under Relative Operating Characteristic (ROC) curve, $p$ value $=$ significance level, $\mathrm{Z}$ is the ratio of estimate to its standard deviation. 
To achieve the practically acceptable level of accuracy of drowsiness detection the detection system could be improved in a number of ways.

- Sensitivity and reliability of measurement of body movement magnitude and spatial patterns should be improved. There are potential benefits in integrating additional sensors at the steering wheel and seat belt;

- Sophisticated signal analysis algorithms should be implemented particularly to deal with the noise and signal artefacts;

- Presented statistical analysis should cover the complete recorded data set and not only episodes of transition to significant drowsiness as conducted at this stage. It is also important to expand the statistical models to the case of multiple categories of drowsiness from the binary model.

However in spite of these deficiencies the authors believe that the presented statistical analysis methodology is the useful starting point that has established associations between drowsiness and noninvasive measures (mainly magnitude of the seat movements) as well as determined the relative effects of various detection techniques and demonstrated benefits of the hybrid approach. With potential improvements in recording accuracy and signal analysis sophistication the described statistical method could still be used to estimate model fit and diagnostic accuracy of more advanced implementations.

\section{ACKNOWEDGEMENT}

We acknowledge support from ARC Linkage grant (LP0347012), Australia.

\section{REFERENCES}

[1] Burton, D., Vigilance Monitoring system, in A.P. Office (ed.) no AU 200022710B2, Australia, 2004.

[2] P.P. Caffier, U. Erdmann, and P. Ullsperger, "Experimental evaluation of eye-blink parameters as a drowsiness measure", Eur J Appl Physiol, 2003, 89(3-4), pp. 319-325.

[3] A. Craig, K. Hancock, et al. "The lifestyle appraisal questionnaire: A comprehensive assessment of health and stress." Psychology \& Health, 1996,11(3): 331 - 343.

[4] J. Connor, P. Norton, S. Ameratunga, E. Robinson, L. Civil, R. Dunn, J. Bailey, and R. Jackson, "Driver sleepiness and risk of serious injuryto car occupants: population based case control study." Br. Med. J. 2002, 324 (7346), pp. 1125.

[5] D. F. Dinges, and R. Grace, "PERCLOS: A valid psychophysiological measure of alertness as assessed by psychomotor vigilance", Federal Highway Administration,
Office of Motor Carriers. Report No. FHWA-MCRT-98-006, 1998.

[6] AJ. Dobson, An introduction to generalised linear models. Chapman Hall. 2002.

[7] L. Fletchar and A. Zelinsky, "Context sensitive driver assistance based on gaze - road scene correlation", International symposium on experimental robotics. Rio de Janeiro Brazil. 2006.

[8] FB. Hu, J. Goldberg, D. Hedeker et al, “Comparison of population-averaged and subject-specific approaches for analysing repeated binary outcomes", Am J Epidemiol. 1998: (147); 694-702.

[9] T. Jung, S. Makeig, M. Stensmo, and T. J. Sejnowski, "Estimating alertness from EEG power spectrum". IEEE Trans. Biomed. Eng. 1997, 44(1), pp. 60-69

[10] S.K. Lal and A. Craig, "A critical review of the psychophysiology of driver fatigue", Biol Psychol, 2001, 55(3), pp. 173-194.

[11] S.K. Lal and A. Craig, "Driver fatigue: electroencephalography and psychological assessment", Psychophysiology, 2002, 39(3), pp. 313-321.

[12] S.K. Lal and A. Craig, "Reproducibility of the spectral components of the electroencephalogram during driver fatigue", Int J Psychophysiol, 2005, 55(2), pp. 137-143.

[13] K.Y. Liang and S. L. Zeger, "Regression analysis for correlated data", Annual Review of Public Health 1993, 14, pp.43-68.

[14] D. McNair, M. Lorr, et al., EDITS manual for the profile of mood states, San Diego, CA, Educational and Industrial Testing Service, 1971.

[18] D. Singer, "Using SAS PROC MIXED to fit multilevel models, hierarchical models and individual growth models", J Educ Behav Statistics. 1998 (24): 323-355.

[19] Spielberger, C. D., R. L. Gorsuch, et al, Manual for the state-trait anxiety inventory, Palo Alto, CA, Consulting Psychologists Press, 1983.

[20] J. A. Stern, D. Boyer, and D. Schroeder, "Blink rate: A possible measure of fatigue", Human Factors, 1994, 36(2), pp. 285-297.

[21] Verbeke, G. and G. Molenberghs, Linear models for longitudinal data. Springer-Verlag. New York. 2000.

[22] W.W. Wierwille and L.A. Ellsworth, "Evaluation of driver drowsiness by trained raters", Accident Analysis \& Prevention, 1994, 26(5), pp. 571-581.

[23] S. Zeger and KY. Liang, "An overview of methods for the analysis of longitudinal data", Stat Med. 1992: (11); 1825-1829.

[15] M. Mahowald, "Eyes wide shut. The dangers of sleepy driving”, Minn.Med. , 2000, 83(3), pp. 25-30.

[16] P.D. Rochford, W. Ruehland, T. Cherchward and R. J. Pierce, "Evaluation of automated versus manual scoring of polysomnographs on sleep disordered breathing". Australian Sleep Association Meeting, 2006.

[17] Santamaria, J. and K.H. Chiappa. The EEG of Drowsiness, Demos Publications, New York, 1987.

[24] E. Zilberg, ZM. Xu, D. Burton, M. Karrar, and S.K. Lal, "Statistical validation of physiological indicators for non-invasive and hybrid driver drowsiness detection system", AusWireless2007, Australia, 2007. 
[25] E. Zilberg, "Analysis of associations between expert rating and physiological indicators of driver drowsiness", Master of Biostatistics Thesis. University of Melbourne, Australia, 2007.

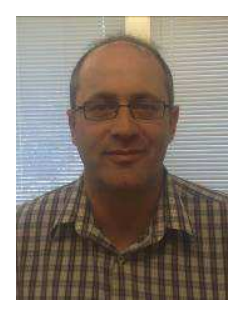

Dr Eugene Zilberg is working for the Australian medical diagnostic company Compumedics as a senior software manager of the Medical Innovation Division. Eugene's areas of expertise include development of intelligent signal processing algorithms and statistical analysis for biomedical applications.

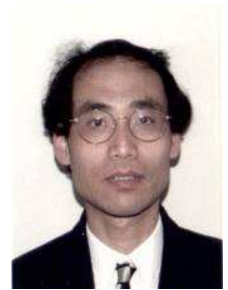

Zheng Ming $\mathrm{Xu}$ received BEng degree in Telecommunication from Nanjing University of Telecommunication, MEng degree in Electrical and Electronic Engineering from Shanghai University, China, in 1982 and 1986 respectively, and $\mathrm{PhD}$ degree in Biomedical Engineering in 1997 from The University of Melbourne, Australia. His research interests include biomedical signal processing, system modelling, biomedical instrument development, and intelligent control application.

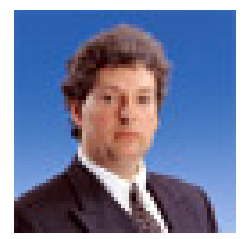

Mr. David Burton has as an Associate Diploma in Electronics from the Royal Melbourne Institute of Technology, a Masters Degree (Eng. Sc.) from Monash University Melbourne, and is currently completing a Phd (Eng. Sc.) in the area of medical technology innovation at Monash University. Mr. Burton is the founder, Chairman and CEO of Compumedics. Mr. Burton's areas of expertise include sleep analysis and sleep disorder, biomedical signal processing and biomedical applications.
Murad Karrar received his Bachelor's degree in Electronics Engineering from La Trobe University in 2001. $\mathrm{He}$ also received his Honours in Computer science in the same year from $\mathrm{La}$ Trobe University. $\mathrm{He}$ is currently a $\mathrm{PhD}$ student in the University of Technology, Sydney. Murad's areas of research are in sleep and fatigue, transportation safety, and sensor and technology development.

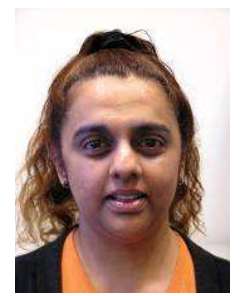

Dr Sara Lal is an academic at the University of Technology, Sydney. Some of Dr Lal's areas of research are neuroscience, cardiovascular, sleep disorder, cognitive function, transportation safety, and sensor and technology development. Dr Lal has attracted various competitive grants and has published a book, book chapters, refereed journals and conference papers 